\title{
¿Son viables los Objetivos del Milenio en el entorno mundial del tercer milenio?
}

\author{
Francisco JaVier IBISATE \\ Departamento de Economía \\ $U C A$, San Salvador
}

RESUMEN: El hecho de que todos los gobiemos del mundo asuman como propios los Objetivos de Desarrollo del Milenio significa aceptar que los grandes modelos no ban sido capaces de enfrentar el reto bumano que ellos implican. De alguna forma volvemos a la bistoria de los sistemas económicos comparados, no el uno contra el otro, como lo bicimos durante las décadas de la guerra fría, sino comparar y enfrentar cada modelo "contra si mismo", sus principios e ideales contra los resultados historicos.
ABSTRACT: The fact that all the govemments around the world assume the Development Aims of the Millenium as their own means that they accept that the great social and economic models have been not able to face the human challenge they imply. In some way, we go back to the history of the economic systems, compared, not one against other, as we used to do during the Cold War decades, but comparing and confronting each model "against itself", this is, its principles and ideals against the historic results.

\section{Un punto de partida}

¿Merece la pena plantearse esta pregunta? Creo que sí y por varias razones. En primer lugar, 191 mandatarios de otros tantos Estados los han firmado y se comprometieron a dar respuestas concretas en el tiempo y en el espacio, unas más cuantitativas y otras más cualitativas. Aceptar estos compromisos significa aceptar que los grandes modelos

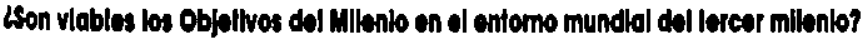


económico-políticos no han logrado dar una respuesta humana a ese cúmulo de problemas. De alguna forma volvemos a la historia de los sistemas económicos comparados, no el uno contra el otro, como lo hicimos durante las décadas de la guerra fría, sino comparar y enfrentar cada modelo "contra sí mismo", sus principios e ideales contra los resultados históricos. Tanto la Economía Social de Mercado como el Estado Social de Bienestar, que entraron en crisis en los años de 1970, están llevando a cabo un proceso de autocrítica que, de alguna manera se refleja en La tercera vía de Anthony Gidens: "La renovación de la socialdemocracia". Los Estados comunistas del Este europeo se descomponen en 1991, por haberse negado —década tras década- al proceso de glasnot, o autocrítica. Lo que está en juego en este tercer milenio es que la globalización neoliberal se niega a compararse "contra sí misma", porque en verdad no puede ser éste "el fin de la historia".

La pregunta se plantea en la misma Declaración del Milenio. "Creemos que la tarea fundamental a que nos enfrentamos hoy es conseguir que la mundialización se convierta en una fuerza positiva para todos los habitantes del mundo, ya que, si bien ofrece grandes posibilidades, en la actualidad sus beneficios se distribuyen de forma muy desigual al igual que sus costos. Reconocemos que los países en desarrollo y los países con economías en transición tienen dificultades especiales para hacer frente a este problema fundamental. Por eso consideramos que sólo desplegando esfuerzos amplios y sostenidos para crear un futuro común, basado en nuestra común humanidad en toda su diversidad, se podrá lograr que la mundialización sea plenamente incluyente y equitativa. Esos esfuerzos deberán incluir la adopción de políticas y medidas, a nivel mundial, que correspondan a las necesidades de los países en desarrollo y de las economías en transición y que se formulen y apliquen con la participación efectiva de esos países y esas economías". ( $\mathrm{N}^{\circ} 5$ )

Esto significa que el punto de partida y el condicionante es el funcionamiento del modelo, sus principios ideológicos y sus parámetros económicos; en este caso, la globalización neoliberal que modela el entorno mundial. Por esta razón, la Declaración del Milenio, antes de detallar los objetivos del "desarrollo y erradicación de la pobreza" $\left(\mathrm{N}^{\circ}\right.$ 19-20), subraya la importancia del marco mundial: "Resolvemos, en consecuencia, crear en los planos nacional y mundial un entorno propicio al desarrollo y a la eliminación de la pobreza" ( $\left.{ }^{\circ} 12\right)$ "El logro de estos objetivos depende, entre otras cosas, de la buena gestión de los 
asuntos públicos en cada país. Depende también de la buena gestión de los asuntos públicos en el plano internacional y de la transparencia de los sistemas financieros, monetarios, comerciales. Propugnamos un sistema comercial y financiero multilateral, abierto, equitativo, basado en normas, previsible y no discriminatorio". ( $\mathrm{N}^{\circ} 13$ )

En el numeral 15 se pide a los países industrializados: "Que adopten (...) una política de acceso libre de derechos y cupos respecto de virtualmente todas las exportaciones de los países menos adelantados. Que apliquen sin más demora el programa mejorado de alivio a la deuda de los países más pobres muy endeudados y que convengan en cancelar todas las deudas bilaterales oficiales de esos países a cambio de que éstos demuestren su firme determinación de reducir la pobreza; y que concedan una asistencia para el desarrollo más generosa, especialmente a los países que se están esforzando genuinamente por destinar sus recursos a reducir la pobreza". ( $\left.\mathrm{N}^{\circ} 15\right)$

Cuando se están redactando los numerales $12-15$ se tiene fresco el recuerdo de la crisis financiera mundial de 1997-1998, que sacudió las bolsas de valores y golpeó economías tan distintas y tan distantes como la Rusia de Boris Yeltsin y el Brasil de Fernando Cardoso, fiel alumno del FMI. En su discurso de apertura, Kofi Annan cita expresamente "las protestas contra la Organización Mundial del Comercio, en Seattle en 1999", donde los 50.000 manifestantes pacíficos califican a la OMC como "la Babilonia del segundo Milenio, una especie de siniestra organización de rostro anónimo, convertida en el motor de una globalización que sólo favorece a las grandes multinacionales". En ese momento se desconoce la historia de las cumbres de la OMC en DohaQatar, Cancún y Hong- Kong. Al redactar la Declaración del Milenio, septiembre 2000, la economía de Estados Unidos resiente los efectos de la burbuja especulativa y en el mes de diciembre Alan Greespan dice: "nuestra tasa de crecimiento probablemente es igual a cero". Las promesas del alivio de la deuda aparecen en una serie de cumbres mundiales; más recientemente en la reunión del G-8 en Gleneagles, Escocia, en julio de 2005. Lamentablemente, el diario El País nos daba una mala noticia: "El Banco Mundial bloquea la condonación de la deuda africana". (13 de febrero de 2006) Estos son unos mínimos datos de una historia mundial que va a imponer serias barreras a la viabilidad de los objetivos del milenio, que aparecen en los numerales 19 y 20 de la Declaración del Milenio. 


\section{Los Objetivos del Milenio}

"Decidimos asimismo: Reducir a la mitad para el año 2015 el porcentaje de habitantes del planeta cuyos ingresos sean inferiores a un dólar por día y el de las personas que padecen hambre; igualmente, para esa misma fecha, reducir a la mitad el porcentaje de personas que carecen del acceso al agua potable o que no pueden costearlo. Velar por que, para ese mismo año, los niños y niñas de todo el mundo puedan terminar un ciclo completo de enseñanza primaria y porque tanto las niñas como los niños tengan igual acceso a todos los niveles de enseñanza. Haber reducido, para ese mismo año, la mortalidad materna en tres cuartas partes y la mortalidad de los niños menores de cinco años en dos terceras partes respecto de sus tasas actuales. Para entonces, haber detenido y comenzado a reducir la propagación del VIH/SIDA, el flagelo del paludismo y otras enfermedades graves que afligen a la humanidad. Prestar especial asistencia a los niños huérfanos por causa del VIH/SIDA. Para el 2020, haber mejorado considerablemente la vida de por lo menos 100 millones de habitantes de tugurios, como se propone la iniciativa "Ciudades sin barrios tugurios". ( $\left.N^{\circ} 19\right)$

"Decidimos también: Promover la igualdad entre los sexos y la autonomía de la mujer como medios eficaces de combatir la pobreza, el hambre y las enfermedades y de estimular un desarrollo verdaderamente sostenible. Elaborar y aplicar estrategias que proporcionen a los jóvenes de todo el mundo la posibilidad real de encontrar un trabajo digno y productivo. Alentar a la industria farmacéutica a que aumente la disponibilidad de los medicamentos esenciales y los ponga al alcance de todas las personas de los países en desarrollo que los necesiten. Establecer sólidas formas de colaboración con el sector privado y con las organizaciones de la sociedad civil en pro del desarrollo y de la erradicación de la pobreza. Velar para que todos puedan aprovechar los beneficios de las nuevas tecnologías, en particular de las tecnologías de la información y de las comunicaciones, conforme a las recomendaciones formuladas en la Declaración Ministerial 2000 del Consejo Económico y Social”. ( $\left.\mathrm{N}^{\circ} 20\right)$

En los numerales comprendidos del 21 al 23 se introduce un importante objetivo: la "protección de nuestro entorno común". Partimos de la hipótesis realista de que no todos los citados Objetivos del Milenio (ODM) se van a alcanzar en las fechas deseadas, como lo podemos percibir en los sucesivos Informes del Desarrollo Humano, a nivel mundial y regional. El trabajo de los buenos estadígrafos es importante porque 
nos suelen dar porcentajes reales, acompañados de explicaciones razonadas, que contradicen el discurso de tantos jefes de Estado especialistas en estadística imaginaria. He trasladado literalmente los numerales afines a los objetivos del milenio porque ahí aparecen algunas relaciones de causa y efecto.

Una nota importante es que la Declaración del Milenio ubica como primera función de la ONU "la paz, la seguridad y el desarme" $\left(\mathrm{N}^{\circ} 8\right.$ 10), de acuerdo al Art. $1^{\circ}$ de la Carta fundacional. "Los propósitos de las Naciones Unidas son: $1^{\circ}$. Mantener la paz y la seguridad internacionales, y con tal fin: tomar medidas colectivas eficaces para prevenir y eliminar amenazas a la paz, y para suprimir actos de agresión u otros quebrantamientos de la paz; y lograr por medios pacíficos, y de conformidad con los principios de la justicia y el derecho internacional, el ajuste o arreglo de controversias o situaciones internacionales susceptibles de conducir a quebrantamientos de la paz". Una triste hipótesis de trabajo, que debemos verificar, es que los principios de derecho internacional y las estrategias que utilizan algunas potencias para proteger su seguridad y paz internas están haciendo más difíciles y menos viables los Objetivos del Milenio, que todos se comprometieron a defender.

\section{Los antecedentes de los Objetivos del Milenio}

En la Declaración del Milenio, todos los delegados firmaron el mismo compromiso: "Creemos que la tarea fundamental a que nos enfrentamos hoy es conseguir que la mundialización se convierta en una fuerza positiva para todos los habitantes del mundo, ya que, si bien ofrece grandes posibilidades, en la actualidad sus beneficios se distribuyen de forma muy desigual al igual que sus costos". El punto de partida es el compromiso de una reforma radical de la globalización, basados en determinados valores que forman parte del derecho humanitario y que han sido discutidos en algunas de las cumbres mundiales organizadas por la ONU en la década de los noventa.

"Consideramos que determinados valores fundamentales son esenciales para las relaciones internacionales del siglo XXI: "La libertad". Los hombres y las mujeres tienen derecho a vivir su vida y a criar a sus hijos con dignidad y libres del hambre y del temor a la violencia, la opresión o la injusticia. La mejor forma de garantizar esos derechos es contar con gobiernos democráticos y participativos basados en la voluntad popular". Se trata de una libertad real que se traduce en una vida digna para la familia y en una democracia participativa para toda la nación. "La 
igualdad". No debe negarse a ninguna persona ni a ninguna nación la posibilidad de beneficiarse del desarrollo. Debe garantizarse la igualdad de derechos y oportunidades de hombres y mujeres. "La solidaridad". Los problemas mundiales deben abordarse de manera tal que los costos y las cargas se distribuyan con justicia, conforme a los principios fundamentales de la equidad y de la justicia social. Los que sufren o los que menos se benefician merecen la ayuda de los más beneficiados".

"La tolerancia". Los seres humanos se deben respetar mutuamente, en toda su diversidad de creencias, culturas e idiomas. No se deben temer ni reprimir las diferencias dentro de las sociedades ni entre ellas; antes bien, deben apreciarse como preciados bienes de la humanidad. Se debe promover activamente una cultura de la paz entre todas las civilizaciones. "El respeto de la naturaleza". Es necesario actuar con prudencia en la gestión y ordenación de todas las especies vivas y todos los recursos naturales, conforme a los preceptos del desarrollo sostenible. Sólo así podremos conservar y transmitir a nuestros descendientes las inconmensurables riquezas que nos brinda la naturaleza. Es preciso modificar las actuales pautas insostenibles de producción y consumo en interés de nuestro bienestar futuro y el de nuestros descendientes. "Responsabilidad común". La responsabilidad de la gestión del desarrollo económico y social en el mundo, lo mismo que en lo que hace a las amenazas que pesan sobre la paz y la seguridad internacionales, debe ser compartida por las naciones del mundo y ejercerse multilateralmente. Por ser la organización más universal y más representativa de todo el mundo, las Naciones Unidas deben desempeñar un papel central a ese respecto". ( $\left.\mathrm{N}^{\circ} 6\right)$

\section{Las cumbres de la ONU en la década de los noventa}

Al cumplirse los 55 años de fundación de la ONU, la Declaración del Milenio tiene especialmente presentes una serie de fenómenos y cumbres mundiales. En 1989 cae el muro de Berlín y en diciembre de 1991 se firma la disolución de la URSS, del pacto de Varsovia y del CAME. Terminaría así la guerra fría para dar inicio a la paz violenta cuando el neoliberalismo se presenta como "el fin de la historia" y en muchos países del mundo se impone el Consenso de Washington.

En 1992 tiene lugar en Río de Janeiro la "Cumbre de la Tierra", actualizando los problemas que ya se habían presentado en el Informe del Club de Roma de 1972. Los 172 delegados de los países miembros 
aprueban tres acuerdos: el Programa 21, la Declaración de Río y los principios relativos a los bosques. Todos estos problemas vuelven a aparecer, en clave mayor; en la Cumbre de la Tierra en Johannesburgo 2002, pese al énfasis puesto por la ONU en la cumbre del Milenio y a la presión ejercida en otras cumbres mundiales. El problema de "la mitigación de los efectos de los cambios climáticos" era parte de la agenda de la LX Asamblea de Naciones Unidas, llevada a cabo en septiembre de 2005, pero ha vuelto a quedar en la vía muerta. (ECA 2005, pp. 862-863) M. Gorbachov, con ejemplos de su inmensa URSS y de otros continentes, describe la "crisis ecológica" en su interesante libro Carta a la tierra. (Ediciones del bronce, Barcelona 2003; pp.60-69)

En 1993, la ONU organiza, en Viena, la Cumbre de los Derechos Humanos, a los que hacen referencia los numerales 24 y 25 de la Declaración del Milenio. En 1994, en El Cairo, tiene lugar la cumbre sobre el crecimiento demográfico, que pesa sobre los países en vías de desarrollo porque la losa del servicio de la deuda externa y las asimetrías del comercio internacional impiden que estos países puedan dedicar los fondos más imprescindibles a la inversión social en salud y educación. En el foro social de Porto Alegre 2002 se dirá: “La especulación financiera y la deuda externa son como las dos losas que impiden el desarrollo de los pueblos, y han recibido las mayores críticas en la primera jornada de trabajo. La deuda externa es impagable e injusta y ya ha sido pagada con el hambre, el dolor y la miseria de nuestro pueblo. Es fundamental no pagar la deuda externa porque el pueblo no la contrajo. Nuestra lucha es difícil, pero no imposible. Se organizó un tribunal popular de seis miembros, entre ellos el Premio Nobel de la Paz, Adolfo Pérez Esquivel. El veredicto fue: "la deuda de estos países es ilegítima, injusta e insostenible", incluso "odiosa"; una noción de derecho internacional que existe desde 1920: "un pueblo puede rechazar el pago de una deuda de un régimen anterior, si se prueba que el gobierno la utilizó para beneficio propio". El concepto de deuda "odiosa" parece estarse aplicando ahora al caso de Irak. (ECA 2002; pp. 72-76)

En la línea de los objetivos del milenio se esperaba que tuviera gran impacto la cumbre sobre el Desarrollo Social, tenida en Copenhague, Dinamarca, en 1995. El logotipo de la cumbre era: "Las sociedades prósperas son las que existen en función del ser humano". Pero la realidad de la globalización se aleja de este ideal. La agenda de la cumbre presenta tres graves problemas: "la pobreza se ha generalizado, disminuye el 
empleo productivo y crece la insolidaridad social". Los datos recogidos por Naciones Unidas son lacerantes, pero la cumbre llegó, pasó y pocos han celebrado su aniversario. ECA le dedicó su editorial de marzo de 1995: "Cómo erradicar la pobreza de la humanidad". "La contradicción principal de la cumbre radica en que, por un lado, dice que quiere erradicar la pobreza; pero por el otro, no puede desembarazarse del esquema neoliberal".

Se habla de la nueva enfermedad de crecimiento con desempleo, es decir, con exclusión de población. Franz Hinkelammert afirma: "Si la exclusión de la población resulta inevitable dentro de cualquier política de crecimiento, hace falta enfrentar la misma economía de crecimiento si se quiere una solución a este problema. Dado el estancamiento dinámico no se puede tener la competencia como criterio central del desarrollo económico. La competitividad resulta en que siempre hay quien gana y quien pierde. Para quien pierde esto equivale a una condena a muerte. Competencia es una especie de guerra. Un desarrollo generalizado no es posible mas que al intervenir los mercados de una manera que aquel que pierda en la competencia no sea condenado a muerte". ("El huracán de la globalización") Juan Somavia, director general de la OIT, dijo en el foro económico de Davos 2006 que el mundo afronta "una crisis global de empleo de enormes proporciones". En El Salvador: " $50 \%$ de empleos son informales". En 2004 aumentó la cifra de trabajadores sin seguros ni AFP. (La Prensa Gráfica, 20 de febrero de 2006; pp. 1-3)

En 1996, la ONU convoca en Beijing, China, a la Cumbre sobre los Derechos de la Mujer, punto central de los objetivos del milenio. Toda la problemática sobre los derechos de la mujer vuelve a aparecer en el foro social de Porto Alegre, tenido en Bombay, India, en enero de 2004. En este foro, los derechos de la mujer india, "ciudadanas de segunda categoría", se enlazan con los delitos que debe juzgar la Corte Penal Internacional. Amal Basha, presidenta de la organización de los derechos humanos de Yemen, explicó que en el mundo árabe la lucha por los derechos humanos es algo muy minoritario y casi exclusivo de las mujeres. "El mundo árabe, dijo, está caracterizado por la cultura opresiva que margina sistemáticamente a gran parte de la población y especialmente a las mujeres, con el pretexto de la sharia" (ley islámica). La Premio Nobel de la Paz, la iraní Shirin Ebani, recordó a las mujeres iraquíes "que sufrieron abusos y discriminación masivos durante el régimen de Saddam Hussein" y que, según ella, "no han visto todavía 
mejorar su situación durante la ocupación norteamericana. Los derechos humanos no pueden importarse por las armas" afirmó. (El País, 21 de enero de 2004)

Kofi Annan, en su discurso de inauguración de la Cumbre del Milenio, hace referencia explícita a la quiebra de dos ejes centrales de la globalización neoliberal. Entre 1997 y 1998, Ja crisis financiera internacional abate las bolsas de valores de las grandes capitales y reconocidos economistas, como Dani Rodrik, Joseph Stiglitz, Paul Krugman, Paul Samuelson y George Soros piden un estricto control de los capitales especulativos, cuya liberalización en nada consta que ayuden al desarrollo de las economías nacionales. En diciembre de 1999, estalla en Seattle la protesta contra la dinámica de las cumbres de la Organización Mundial del Comercio, donde los mandatarios de los países industrializados imponen la agenda a tratar y aprobar. Los delegados de países pobres y emergentes se negaron a firmar un documento final "que ni habían tenido tiempo de leer". El fantasma de Seattle sigue sobrevolando las cumbres de Doha 2001, Cancún 2003 y Hong Kong 2005. La teoría del libre comercio sigue siendo un fraude intelectual.

En noviembre de 1999, el Congreso de la Internacional Socialista, que engloba 170 organizaciones, redacta la Declaración de París, recogiendo seis grandes bloques de problemas con que cierra el siglo $\mathrm{XX}$ : 1) Lucha contra la pobreza y el hambre, contra la explotación y la desigualdad de acceso a los recursos económicos y tecnológicos mundiales. Anulación de la deuda de los países pobres. 2) Lucha por los derechos humanos y la democracia; avanzar en el derecho de injerencia por razones humanitarias; no amparar la impunidad de los dictadores. 3) La construcción de la paz y la seguridad a través de un nuevo orden internacional. 4) Reforma de la ONU y ampliación del número de miembros del Consejo de Seguridad. Reforma del FMI y del BM, de la OMC, para adaptarlas a las nuevas realidades. Asegurar una mayor transparencia del sistema financiero internacional a través de reglas. Lucha contra el crimen organizado, el tráfico de drogas y el blanqueo de dinero. Creación de un Consejo de Seguridad Económica en la ONU. 5) Dar respuestas rápidas y sostenidas en el tiempo al problema de la protección del ecosistema. 6) Europa anticipa un modelo de regionalismo abierto para hacer frente a los desafíos a los que no pueden responder eficazmente los estados-naciones. Fomento de este modelo en América Latina, Asia y África". (El País, 9 de noviembre de 1999) La mayoría de estos puntos pasan a ser materia prima para la Declaración del Milenio. 
En el mes de febrero 2000 tiene lugar la conferencia de la UNCTAD sobre comercio y desarrollo en Bangkok, Tailandia, donde había estallado la crisis financiera en 1997. Michel Camdessus, presidente del FMI, es recibido con un pastelazo de crema tailandesa en pleno rostro: "Son gajes del oficio", dijo y echó su discurso de despedida, del cual reproduzco un breve párrafo, porque preludia el problema que aquí tratamos de despejar: "¿Por qué tanta ansiedad y por qué tantos la rechazan (la globalización) como un símbolo de las nuevas tendencias económicas? La respuesta es que aún no se ha demostrado que la globalización se preocupe lo suficiente por el problema más grave de esta era, la pobreza, o que sea capaz de resolverlo. La creciente brecha entre los ricos y los pobres y el abismo que separa a los más ricos de los más pobres, son moralmente inadmisibles, económicamente ineficientes $y$, desde un punto de vista social, potencialmente explosivos. Hoy es evidente que no basta aumentar el tamaño de la torta; la forma en que se reparte es esencial para el dinamismo del desarrollo. Si no ofrecemos esperanza a los pobres, la confrontación, la violencia y las conmociones civiles terminarán socavando la estructura de la sociedad. En ninguna parte podemos permitirnos el lujo de hacer caso omiso de la pobreza, pero es en los países más pobres donde ya no puede tolerarse la extrema pobreza".

Rubens Ricupero, Secretario General de la UNCTAD, expone a representantes de países desarrollados que el escenario, las normas y el funcionamiento mismo de la globalización dificultan la integración de los países en desarrollo al proceso de comercialización global. Se unen una serie de deficiencias en el entorno externo y de limitaciones internas al desarrollo. Estas serían, en forma sintética, algunas de las deficiencias externas y limitaciones internas.

La liberación de los capitales privados, seguida de la crisis financiera mundial, ha dañado más a las naciones pobres y emergentes que no cuentan con sólidas instituciones económicas y financieras. Con la mundialización de los mercados de capitales en las dos últimas décadas se reduce y se atrofia la ayuda oficial al desarrollo (AOD), siendo aquellos capitales un sustituto imperfecto de las ayudas oficiales. En las presentes décadas estas ayudas han disminuido en términos reales e incluso nominales y tampoco se destinan en proporción mayor a los 
países más pobres. Por añadidura esto sucede cuando los países pobres soportan la carga de una deuda externa que ni pueden atender, ni pueden negociar con sus acreedores.

A estas presiones financieras se suman las relaciones asimétricas adoptadas en el marco de la Organización Mundial del Comercio, que desató la cólera y el rechazo de Seattle, porque sirven y propician el desarrollo de los países ya desarrollados. Las nuevas tecnologías son aseguradas con Derechos de Propiedad Intelectual; derechos onerosos para los países pobres e imposibles para los más pobres. Contraria es la situación de los productos que interesa exportar a los países en desarrollo, especialmente alimentos y fibras textiles. Ha disminuido sensiblemente la demanda de los productos básicos en el comercio internacional, mientras que otras exportaciones tradicionales se ven sometidas a ciclos alternativos que desorientan y desaniman su producción. Falla el primer requisito, fundamento del comercio interno e internacional: la especialización en el trabajo que hoy día se centra en el conocimiento y la inversión tecnológica. Muchos países en desarrollo son incapaces de afrontar este desafío y poder cumplir en forma significativa con las normas exigidas en el marco de la OMC.

La teoría y la praxis impuesta recomendaba que el Estado dejara de intervenir directamente en las actividades productivas y adoptara medidas de amplia liberalización de la actividad económica, incluido el comercio exterior, a fin de que los mercados pudieran fijar los precios adecuados. Sin embargo, cada vez es más evidente que estos elementos distan mucho de ser suficientes. De ahí surge la pregunta: ien qué medida deben ser uniformes los modelos de desarrollo? Con la desregulación, la privatización y la liberalización de los mercados se pretendía solucionar todos estos problemas. Pero no ha sido éste el resultado. La ausencia de Estado no garantiza la libre competencia, ni el buen funcionamiento de los mercados. A los países del Tercer Mundo, es decir, a sus gobiernos, se les ha engañado con la imagen distorsionada del concepto-paradigma de mercado. Dada su rápida transformación cuantitativa y cualitativa los países en desarrollo descubren, a costa propia, que el mercado no es un buen paradigma y por tanto no es un "modelo". (Entomo económico mundial. UCA Editores 2005; pp. 155163) Cinco años después, la globalización sigue haciendo más difícil la globalización. 
6. El "Consenso de Monterrey": Financiar el desarrollo y el alivio de la pobreza

En marzo de 2002 tiene lugar en Monterrey, México, la Conferencia Internacional dedicada al financiamiento del desarrollo y al alivio de la pobreza. Reconocidos expertos como George Soros, Joseph Stiglitz y Michel Candessus, sugirieron nuevas fuentes de financiamiento del desarrollo y alivio de la pobreza. El estallido de la burbuja en la bolsa de valores de Estados Unidos en el segundo semestre del año 2000 da por resultado que el punto central del foro económico de Davos 2001 sea "recuperar el crecimiento y corregir las desigualdades sociales". Luego de los atentados terroristas del 11 de septiembre se tiene conciencia de que la contracción económica afectará más gravemente a las economías en desarrollo. En este entorno se prepara el proyecto de documento final de la Conferencia Internacional sobre el Financiamiento del Desarrollo, con participación de sesenta y seis jefes de Estado. He aquí un resumen del documento final, por tratarse de una cumbre específicamente organizada con miras a financiar el desarrollo y el alivio de la pobreza:

"Nos comprometemos a aplicar políticas racionales, instaurar el buen gobierno y asegurar la primacía del derecho. Nos esforzaremos por movilizar los recursos nacionales, atraer flujos internacionales, promover el comercio internacional, que es el motor del desarrollo; intensificar la cooperación financiera y técnica internacional para el desarrollo; un financiamiento viable y un alivio de la deuda externa; reforzar la coherencia de los sistemas monetarios financieros y comerciales internacionales. Los ataques terroristas del 11 de septiembre han agravado la desaceleración de la economía mundial. Nuestra voluntad de trabajar unidos es más fuerte que nunca. La mundialización ofrece perspectivas así como problemas. Los países en desarrollo y los emergentes se enfrentan a dificultades mayores. La mundialización debiera beneficiar a todos en forma equitativa. Un buen gobierno es la primera condición para un desarrollo durable. Una prioridad es la lucha contra la corrupción a todos los niveles. Un sistema comercial multilateral y universal, bien reglamentado y abierto, no discriminatorio y equitativo, concebido como un verdadero instrumento de la liberación del intercambio, puede ser un gran factor favorable para el desarrollo mundial". (Le Monde, 22 de marzo de 2002). 
En el alivio de la pobreza la primera palabra la tienen los donantes y abundaron las palabras. Jacques Chirac, presidente de Francia, habló de "la defensa de la mundialización de la solidaridad". "Nuestro mundo se enfrenta con el terrorismo fanático, con los poderosos tentáculos del crimen organizado y de los traficantes de droga. Las naciones que temen ver su identidad laminada por la aplanadora de una mundialización incontrolada a veces buscan refugiarse en la nostalgia de tiempos pasados. Lo que está en juego en Monterrey no es sólo el financiamiento del desarrollo. Es la unificación de los Estados ante la cuestión más hiriente de nuestro tiempo. ¿Cómo poner fin a una situación moralmente inaceptable, políticamente peligrosa, económicamente absurda, que es un mundo donde la acumulación creciente de riquezas no es capaz de hacer que los más pobres salgan de la pobreza?". El Secretario del Tesoro británico, Gordon Brown, pide a la comunidad internacional realizar "una guerra contra la pobreza. Hay un acuerdo creciente en que, igual que luchamos juntos contra el terrorismo, debemos luchar juntos contra la pobreza".

El discurso más esperado era el del presidente Bush: "Estoy aquí para reafirmar la voluntad de los EEUU de llevar la esperanza y abrir los horizontes de los pueblos más necesitados e invitar a poner en marcha un nuevo pacto para el desarrollo, que se caracterice por una mayor responsabilidad de los países ricos como de los países pobres. Los países en desarrollo necesitan un acceso más amplio a los mercados de los países ricos". (En esos mismo días se debatía en la sede de la OMC en Ginebra los aranceles impuestos por EEUU a las importaciones de acero) "Nosotros luchamos contra la pobreza con la esperanza de que ello sea una respuesta al terrorismo. Atacamos la pobreza, la indigencia, la falta de educación y a los ineficientes gobiernos que, con frecuencia, permiten que se den situaciones que los terroristas aprovechan para su causa. Desde hace años el éxito de la ayuda al desarrollo se ha medido por el monto de los recursos gastados. Verter dinero sobre un estéril inmovilismo poco ayuda a los pobres e incluso puede retrasar las reformas y el progreso. La pobreza no es la causa del terrorismo. Sin embargo, una pobreza persistente y la represión pueden llevar a la desesperación. Debemos unir una ayuda mayor con las reformas políticas, jurídicas y económicas. Las naciones desarrolladas tienen el deber no sólo de distribuir su riqueza, sino también de promover las fuentes que promueven la riqueza: libertad económica, libertad política, Estado de derecho y derechos del hombre". 
Este discurso encierra un cúmulo de oscuridades y medias verdades. A sugerencia de Paul O'Neil, Secretario del Tesoro, 50\% de las ayudas a los países más pobres deberían ser donaciones no reembolsables, con lo cual se estaría cerrando la fuente de ingresos del BM para seguir haciendo préstamos. El presidente del BM, James Wolfensohn, afirma no estar en contra de donaciones en ciertas circunstancias (pandemias y casos de posguerra) y todo depende de la generosidad de los accionistas. Lo que está detrás de esta tesis de la Administración Bush es la postura de la Comisión Meltzer, que recomienda reducir el papel del FMI y $\mathrm{BM}$ a lo que fueron sus objetivos fundacionales: el FMI se centraría en ayudar al equilibrio de las balanzas de pagos y el BM en aportar préstamos de reconstrucción a países más retrasados. Esta tesis olvida que los destinatarios de 1945 eran los países europeos, capaces de rehacer sus economías en breve espacio de tiempo. Los destinatarios de 1980-1990 son la creciente mayoría de países en vías de desarrollo, gravados con la impagable losa de la deuda externa y para quienes la fuente del libre mercado de los capitales privados está cerrada.

En segundo lugar, aunque el presidente Bush afirme la existencia de un estrecho nexo entre pobreza persistente y gestación del terrorismo, lo cierto es que en todas las cumbres mundiales presiona al resto de naciones para que concentren toda su atención en la lucha contra el terrorismo, dejando en la vía muerta todos los pactos y compromisos para financiar el desarrollo y el alivio de la pobreza. Esta ha sido su trayectoria desde el 11 de septiembre 2001 hasta el 18 de diciembre 2005, en que hace aguas la cumbre de la OMC en Hong Kong. Por añadidura, la solución de la pobreza está en la libertad política y económica y en el libre comercio, que genera libertad, democracia y desarrollo, tal como lo vino a predicar a San Salvador, en ese mismo mes de marzo 2002. En la agenda de Monterrey se dedica una amplia agenda al tema: el comercio internacional como promotor del desarrollo.

El documento de Monterrey, en su numeral 13, enuncia un nuevo compromiso: "Una de nuestras prioridades es la lucha contra la corrupción en todos los niveles. La corrupción es un grave obstáculo que entorpece la movilización y asignación eficiente de recursos que deberían destinarse a actividades indispensables para erradicar la pobreza y promover el desarrollo económico sostenible”. En este aspecto, Monterrey viene a avalar las propuestas presentadas en los foros sociales de Porto Alegre 2001-2002. El gobierno de los EEUU es uno de los que más ha 
insistido en el tema de la corrupción en los países pobres, olvidando que los países donantes fueron culpables de dicha corrupción al financiar a gobiernos afines políticamente, a sabiendas de que esas ayudas no llegaban a los pobres. He aquí algunos testimonios.

"Un tema pendiente es la forma en que se puede repatriar recursos económicos sacados de los países en vías de desarrollo y transferidos a bancos de países industrializados", dijo Kofi Annan. La conferencia de Monterrey "pretende profundizar el actual proceso hacia la reestructuración de pagos y la eventual condonación de la servidumbre de los préstamos concedidos en su día a sátrapas y bandoleros con despacho de ministro. La carga es intolerable en América Latina", Junto con el caso de Irak, en varios países de América Latina se pudiera aplicar el derecho de no tener que pagar una "deuda odiosa".

"El realismo busca en México medidas más audaces contra la ayuda externa que, en buena medida, apuntaló dictaduras y populismos, enriqueció a presidentes, funcionarios y empresarios cómplices, fue transferida a cuentas suizas o absorbida por el analfabetismo político". "Pero también es cierto que los países industrializados cometieron muchos errores en la ejecución de programas de ayuda a sus ex colonias, según admiten los gobiernos donantes. El dinero fue concedido a tiranos, a funcionarios ladrones o se perdía en los vericuetos de la corrupción". Sin viajar por África, en América Latina podemos ofrecer una larga lista de personajes con "maestría en el pillaje", desde algunos presidentes de México hasta el dictador Pinochet. ("El Consenso de Monterrey: financiar el desarrollo". Realidad, 2002, N 86; Pp. 131-154) Esto significa que tan importante como hacer estadísticas sobre la situación de la pobreza en cada país -investigación siempre necesaria- sería indispensable dedicar la misma atención a despejar las fuentes de la corrupción en las burocracias públicas y privadas. El gran problema es que los pobres son débiles y los corruptos, en general, son poderosos. Esta es una de las razones por las que en el continente latinoamericano es tan difícil aprobar políticas que reduzcan la desigualdad económica, social y política.

\section{7. "El peor genocidio que la humanidad ha conocido"}

La afirmación viene entre comillas por ser Vandana Shiva, directora de la fundación para la Ciencia y la Ecología de India, quien la hiciera en el discurso que pronunció en el foro económico de Davos 2001. Vandana afirmó que el actual proceso de globalización, especialmente 
las barreras que imponen los países ricos a los productos agrícolas de los más miserables constituyen un "genocidio en una escala que la humanidad nunca ha conocido". La India, dijo Vandana, está levantando las últimas restricciones a las importaciones a partir del $1^{\circ}$ de abril de 2001, en cumplimiento de las normas de la OMC, a pesar de que los países industrializados no levantarán las que pesan sobre productos textiles hasta 2005. "Estamos pagando un alto precio en términos de democracia. Porque con su globalización consiguen como respuesta la violencia y entonces necesitan Estados policiales para defender este trato injusto". Joseph Stiglitz, Premio Nobel de Economía, dijo esto mismo, en forma más suave: "La teoría del libre comercio es un fraude intelectual". Stiglitz usa muchas veces la palabra "hipocresía" para cualificar el comportamiento del comercio internacional.

Luego del fracaso de Seattle,1999, algo de esta falsa misericordia y compasión aparece en la "Declaración Ministerial de la Organización Mundial del Comercio", en Doha, noviembre 2001. "El sistema multilateral de comercio plasmado en la $\mathrm{OMC}$ ha contribuido de manera significativa al crecimiento económico, al desarrollo y al empleo a lo largo de los últimos 50 años. En consecuencia, reafirmamos enérgicamente los principios y objetivos enunciados en el Acuerdo de Marrakech por el que se establece la OMC, y nos comprometemos a rechazar todo el recurso al proteccionismo. El comercio internacional puede desempeñar una función de importancia en la promoción del desarrollo económico y el alivio de la pobreza. Reconocemos la necesidad de que todos nuestros pueblos se beneficien del aumento de las oportunidades y los avances del bienestar que genera el sistema multilateral de comercio. La mayoria de los miembros de la OMC son países en desarrollo. Pretendemos poner sus necesidades e intereses en el centro del Programa de Trabajo adoptado en la presente Declaración. Recordando el preámbulo del acuerdo de Marakech, continuaremos realizando esfuerzos positivos para que los paises en desarrollo, $y$ especialmente los menos adelantados, obtengan una parte del incremento del comercio internacional que corresponda a las necesidades de su desarrollo económico".

"Reconocemos la particular vulnerabilidad de los países menos adelantados y las dificultades estructurales especiales con que tropiezan en la economía mundial. Estamos comprometidos a hacer frente a la marginación de los países menos adelantados en el comercio internacional y a mejorar su participación efectiva en el sistema multilateral de comercio. 
Recordamos los compromisos asumidos por los Ministros en nuestras reuniones de Marrakech, Singapur y Ginebra, y por la comunidad internacional en la Tercera Conferencia de las Naciones Unidas sobre los países menos adelantados celebrada en Bruselas para ayudar a los países menos adelantados a lograr una integración provechosa y significativa en el sistema multilateral de comercio y en la economía mundial (...) Estamos convencidos de que los objetivos de respaldar y salvaguardar un sistema multilateral de comercio abierto y no discriminatorio, y de actuar para la protección del medio ambiente y la promoción del desarrollo sostenible pueden y deben apoyarse mutuamente".

A continuación se programan las discusiones de una serie de puntos que pueden ser más espinosos: agricultura, servicios, acceso a los mercados para productos no agrícolas, derechos de propiedad intelectual, comercio e inversiones, comercio y política de competencia, transparencia de la contratación pública, facilitación del comercio, normas de la OMC, solución de diferencias. Como botón de muestra, en relación a las masivas subvenciones a las exportaciones agrarias $(\$ 300.000 \mathrm{mi}-$ llones anuales), los países miembros de la OMC "nos comprometemos a celebrar negociaciones globales encaminadas a lograr; mejoras sustanciales del acceso a los mercados, reducciones de todas las formas de subvenciones a la exportación, con miras a su remoción progresiva, y reducciones sustanciales de la ayuda interna causante de distorsión del comercio". ( $\left.\mathrm{N}^{\circ} 13\right)$

Dos años más tarde, quiebra la OMC de Cancún, en septiembre de 2003, porque no se han reducido, sino que han incrementado las masivas subvenciones. La tensión sube al prepararse la OMC de Hong Kong, diciembre 2005; el programa queda prácticamente reducido a este sólo punto y los EEUU reducirán sus masivas subvenciones al algodón tal vez en 2006 y Europa promete considerar la reducción en el año 2013. Mientras tanto millones de cultivadores de algodón en África y de campesinos agrícolas en América Latina siguen en el desempleo y la indigencia. (Realidad 2005, $\mathrm{N}^{\circ} 106$ ) Como dijera Vandana Shiva: éste es el peor genocidio que ha conocido la humanidad. Joseph Stiglitz se dirige a los miembros del G-7 reunidos en Génova, en julio de 2001: "El sistema de comercio global está en problemas. Se predica el libre comercio como el evangelio en todas partes, pero parece que los países no hacen caso de su propio mensaje; sus mercados permanecen cerrados a muchos de los productos de los países en desarrollo, subsidian a sus 
agricultores en forma masiva, lo que hace imposible que los países en desarrollo puedan competir. El mensaje del G-7 parece ser: hagan lo que decimos, no lo que hacemos". (El País, 15 de julio de 2001).

En el foro económico de Davos 2003 dicen que el discurso más aplaudido fue el de Lula da Silva: "Desde esta montaña mágica (las alturas de Davos) les invito a mirar el mundo con otros ojos, a crear un modelo de desarrollo que responda a las necesidades de millones de personas que viven al margen del desarrollo. Si ustedes quieren ser coherentes, ustedes no pueden y no deben plantar barreras a los países en desarrollo. Queremos un libre comercio que se caracterice por la reciprocidad. De nada valdrá el esfuerzo exportador que hagamos si los países ricos continúan predicando el libre comercio y practican el proteccionismo. Si los países ricos son negociadores duros, tampoco nosotros podremos hacer concesiones. No tiene sentido invertir si cuando vas a exportar te enfrentas con enormes barreras. No queremos ser tratados como ciudadanos de segundo orden, sino iguales. Es urgente construir un nuevo orden económico con más justicia, un nuevo programa para el desarrollo mundial compartido, una nueva ética. Aquí en Davos no hay ahora mas que un 'dios', el libre mercado, pero el mercado libre debe tener como corolario la libertad y la seguridad de la población". Lula abogó para que "prevalezcan los valores del humanismo en las relaciones entre países y pueblos". En ese mes de enero de 2003 sobrevolaba el fantasma de la guerra contra Irak.

El pasado noviembre de 2005 fracasa en Mar del Plata la cumbre de los países miembros del Área del Libre Comercio de las Américas (ALCA), aunque en la agenda no aparecía la discusión del ALCA, sino otros temas como el empleo. Da la impresión de que algunos jefes de Estado y ministros de Economía desconocen la letra pequeña del ALCA, cuyo programa y plan de acción se presenta en la Cumbre de Québec, abril 2001. Conviene resaltar que en los objetivos del ALCA se integran una serie de compromisos sociales que traducen casi literalmente los Objetivos del Milenio. Los objetivos comerciales vienen entretejidos con los siguientes pactos sociales. "Transparencia en las relaciones entre las instituciones y los ciudadanos, dando mayor participación a la sociedad civil; cooperación en materia de derechos humanos; promoción de los derechos civiles, económicos, políticos y sociales de la mujer y de los pueblos indígenas; acceso universal a sistemas de justicia imparciales e independientes y la necesidad de recurrir a éstos 
para resolver conflictos; creación de prosperidad con la mayor zona de libre comercio del mundo, 800 millones de personas; promoción de los principios de inclusión y equidad, así como la mejora de las condiciones de trabajo, el respeto de las normas laborales y la cooperación en las cuestiones relacionadas con la migración; estudiar la adopción de iniciativas destinadas a garantizar la buena gestión de las empresas privadas y su responsabilidad social; mejorar los sistemas de transporte del hemisferio; enfoques comunes en cuanto a la energía; estrechar la cooperación en cuestiones medioambientales; realización del potencial humano, que permita mejorar el nivel de vida de todos los ciudadanos, apoyando la iniciativa de reducir a la mitad, antes de 2015, el número de personas que viven en la pobreza en todo el continente; acceso al empleo y facilitar que los ciudadanos adquieran las actitudes necesarias para competir en el contexto de una economía mundial, basada en el conocimiento; soluciones prácticas a la 'brecha comercial' existente en el hemisferio; enfatizar el acceso a la educación, la asistencia médica, así como proteger y promover la diversidad cultural". ("Agenda de la Cumbre de Québec"; BBC Mundo; 19 de abril 2001. ECA 2001; pp. 700-701)

¿Por qué es importante para nosotros el recuerdo de esta letra pequeña? Cuando en noviembre de 2003 tiene lugar en Miami la reunión para aprobar el programa del ALCA, la Declaración Ministerial vuelve a subrayar los aspectos sociales de esta integración comercial. "Afirmamos que las negociaciones del ALCA tomarán en cuenta el programa social y económico global contenido en las Declaraciones y Plan de Acción de Miami, Santiago y Québec, con miras a contribuir a la elevación del nivel de vida, al aumento del empleo, a la mejora de las condiciones de trabajo de todos los pueblos de las Américas, al fortalecimiento del diálogo social y de la protección social, a la mejora de los niveles de salud y de la educación y a una mejor protección del medio ambiente (...) Somos conscientes de que las negociaciones deben buscar la conclusión de un acuerdo equilibrado que aborde el problema de las diferencias en los niveles de desarrollo y tamaño de las economías del hemisferio por medio de disposiciones y mecanismos diversos".

¿Qué disposiciones y mecanismos? Gracias a las presiones hechas por el representante de Brasil y MERCOSUR, Celso Amorim, frente a Robert Zoellick, representante de EEUU, se constituyeron ocho grupos de negociaciones para otros tantos puntos espinosos del libre comercio, 
que coinciden con los puntos señalados en la Declaración Ministerial de Doha: acceso a los mercados, agricultura y subvenciones, inversiones, política de competencia, derechos de propiedad intelectual, servicios, reglamento de diferendos. En la cumbre tenida en Miami, noviembre 2003, se determina que para ratificar el ALCA en 2005 es necesario que previamente se llegue a un acuerdo en estos puntos espinosos, que no pueden imponerse a todos los países. En las mismas fechas, luego del fracaso de la OMC en Cancún, septiembre 2003, nuestros Ministros de Economía firman con el mismo Robert Zoellick el TLC con EEUU, donde los temas espinosos entran suavemente sin mayor información y discusión. (Entorno económico mundial; pp. 280-285) En noviembre de 2005 vuelve a fallar el intento de ratificar el ALCA en Mar del Plata, al mismo tiempo que iniciamos triunfalmente el TLC en marzo de 2006, dos meses después del sonoro fracaso de la OMC en Hong Kong. El libre comercio internacional en nada está ayudando a la viabilidad de los objetivos del milenio.

\section{El respeto de la naturaleza}

La Declaración del Milenio dedica los artículos 21 y 22 a la protección de nuestro entorno común, donde se hace referencia a la Conferencia de Naciones Unidas sobre el Medio Ambiente y el Desarrollo, Río de Janeiro, 1992, al mismo tiempo que se invita a todos los Estados a ratificar el Protocolo de Kyoto. Sabemos que el país responsable del $25 \%$ de la contaminación mundial se niega, hasta el momento, a ratificar el Protocolo de Kyoto. En agosto de 2002 riene lugar la Conferencia de Naciones Unidas sobre la Tierra en Johannesburgo. Los discursos de J. Chirac y G. Schröder guardan plena actualidad y las referencias estadísticas impresionan.

He aquí unas líneas del artículo de Ignacio Ramonet titulado "Salvar el planeta": "El desarrollo durable supone la aplicación de tres principios; el principio de precaución, que busca más bien prevenir que reparar; el principio de solidaridad entre las generaciones actuales y futuras y entre las poblaciones del mundo; y el principio de participación de todos los actores sociales en la toma de decisiones". Diez años después de Río de Janeiro no ha mejorado la situación. "Todo lo contrario. Con la aceleración de la mundialización liberal ha crecido el esquema inviable de consumo y producción. También crece la contaminación creada por el mundo rico sobre la biosfera. Sus emanaciones de gas, de efecto invernadero, son diez veces mayores que las de los países del Sur (...) 
Más de mil millones de personas no disponen de agua potable y casi tres mil millones de personas no disponen de agua potable y casi tres mil millones consumen agua contaminada. Debido a la ingestión de esta agua 30.000 personas mueren cada día. Son diez veces más, cada día, que el número de víctimas de los odiosos atentados del 11 septiembre".

"Prosigue la devastación de los bosques; cada año desaparecen 17 millones de hectáreas, cuatro veces la superficie de Suiza. Como los árboles no están allí para absorber los excedentes del $\mathrm{CO}_{2}$ (gas carbónico) se agrava el efecto invernadero y el recalentamiento de la tierra. Cada año se extinguen 6.000 especies animales. Amenaza la extinción masiva (13\% de pájaros; $25 \%$ de mamíferos; $34 \%$ de peces), como nunca la tierra lo había conocido desde la desaparición de los dinosauros". Lo más triste de esta conferencia fue que, por presión de los países petroleros, no se llegó al propuesto acuerdo de que el $15 \%$ de los combustibles debían ser energías limpias; ahora sentimos sus efectos. (Entorno económico mundial; pp. 232-236) Es claro que este objetivo del milenio queda en la vía muerta por claro descuido de países desarrollados y subdesarrollados, como es el caso de El Salvador.

Dado que hoy día se habla tanto de la amenaza nuclear merece la pena leer unos apuntes de Greenpeace sobre residuos nucleares. "Se producen residuos nucleares en cada una de las etapas del ciclo del combustible nuclear, desde la minería del uranio al reprocesamiento del combustible nuclear irradiado. La mayor parte de la basura nuclear permanece siendo peligrosa por miles de años, dejando así una peligrosa herencia a las futuras generaciones. Como parte de su operación rutinaria, toda central nuclear descarga algunos de sus materiales directamente al ambiente. Algunos residuos líquidos se descargan con el agua de refrigeración de las turbinas hacia el mar, ríos y lagos, y otros residios gaseosos se liberan a la atmósfera".

"Según cálculos de la Agencia Internacional de Energía Atómica (AIEA), la cantidad global de combustible nuclear en la actualidad ronda las 200.000 toneladas. Se cree que llegará a unas 450.000 toneladas para mediados del siglo XXI. A pesar de que se han estudiado una variedad de métodos para disponer de estos residuos durante las últimas décadas -incluido arrojarlos al espacio- no existe aún una solución acerca de qué hacer con esta basura nuclear. La mejor solución para el futuro es que no debería producirse más basura nuclear a nivel mundial. Durante las próximas tres décadas más de 350 reactores deberán salir de 
servicio. Ya van más de 40 años desde que el primer reactor comercial comenzó a producir electricidad y la industria no tiene respuesta sobre cómo hacer seguro y económico el desmantelamiento de un reactor". (Realidad 2005; p. 203)

A la degradación medioambiental, claramente descrita en Río de Janeiro y en Johannesburgo, se suma ahora la amenaza nuclear con un doble efecto. Valga, en primer lugar, la reflexión de M. Gorbachov, en cuyo primer año de mandato en la URSS estallan los reactores nucleares de Chernobil, en abril de 1986: "En segundo lugar, mi fe en la absoluta seguridad de la técnica se vio gravemente quebrantada. Durante treinta años nos habían estado convenciendo, según la gráfica expresión del académico A. Alexandrov, de que 'el átomo usado con fines pacíficos no era más peligroso que un samovar', y que se podía levantar una central nuclear incluso en la propia plaza Roja". Avalando el breve testimonio de Greenpeace, Gorbachov continúa afirmando: "A los científicos dedicados a la física los teníamos casi por unos dioses que, ayudados por la ciencia, habían conseguido realizar el sueño centenario de la humanidad de disponer de una energía eléctrica barata y 'pura'. Pero resultó que los dioses, para decirlo con una metáfora, resultaron ser vulnerables y estar sujetos a las debilidades humanas. Ello me convenció de la necesidad de que la sociedad civil controle todos aquellos procesos susceptibles de influir en la salud y la vida de la población". (Carta a la tierra; p. 42)

El segundo efecto es, en expresión de $\mathrm{M}$. Gorbachov, que aumenta el número de países que desean integrarse en "el club nuclear" y ello por un doble motivo. Todo país tiene derecho - bajo el control de la Agencia Internacional de Energía Atómica (AIEA) - a desarrollar la energía nuclear con fines civiles de generación de electricidad, aunque ello viene a hacer más peligroso el manejo de los residuos sólidos nucleares. El segundo motivo nos lleva al epicentro de la gran amenaza mundial: muchos autores piensan que Estados Unidos y la OTAN no hubieran lanzado la 'guerra humanitaria' de Serbia-Kosovo en 1998, ni Estados Unidos e Inglaterra hubieran llevado a cabo la invasión de Irak en 2003, si Yugoslavia e Irak hubieran dispuesto de la bomba atómica. Un caso concreto en los años 2005-2006 es lo que pueda hacer el Gobierno de Irán, presionado por potencias que disponen de la bomba atómica desde hace cincuenta años. Esto sí nos está llevando al epicentro del miedo y de la violencia de los que amenazan y de los amenazados. En este escenario los objetivos del milenio pasan a un segundo plano. 
Partimos del hecho de que hay una cercana similitud entre los delitos juzgados y condenados en los Estatutos del Juicio de Nüremberg de 1945, y los delitos que deben juzgarse y condenarse conforme a los estatutos de la Corte Penal Internacional; desde el $1^{\circ}$ de julio de 2002; en ambos casos se trata de crímenes de guerra, crímenes contra la paz y crímenes de lesa humanidad, así como el genocidio. Se trata de terrorismos de Estado, citados implícitamente en el discurso de Kofi Annan, al presentar la Declaración del Milenio: "El instinto de solidaridad humana -que impulsa a algunos Estados a acudir en ayuda de los ciudadanos de otros Estados o a presentar cargos contra sus antiguos dictadores- es digno de alabanza. Pero cuando estas acciones las aplican uno o pocos Estados en nombre de su propia autoridad, traen consigo el riesgo de la anarquía mundial". Esta clase de crímenes - y esta anarquía mundialha sido algo propio de las grandes potencias del pasado siglo $\mathrm{XX}$ y del presente tercer milenio. Es el terrorismo de Estado, en cuanto Estado.

El fenómeno del terrorismo se ha convertido en uno de los ejes centrales de los mensajes de los Papas Juan Pablo II y Benedicto XVI, como he tratado de mostrarlo en el artículo "Sin verdad no hay paz ni justicia social". ( $E C A$, enero- febrero 2006) Lo que aquí deseo mostrar es que, a partir del 11 de septiembre 2001, la amenaza de este terrorismo, sobre todo a Estados Unidos, desbanca la atención que las naciones más poderosas debieran prestar a los objetivos del milenio. En la Asamblea General de Naciones Unidas, 10 de noviembre de 2001, "Bush urge a la ONU a sumarse a la batalla contra el terrorismo. Toda una generación tiene hoy el deber de acabar para siempre con una amenaza planetaria. Quien no se sume a esta lucha pagará sus consecuencias". (El País, 11 de noviembre de 2001).

El foro económico de Davos celebrado en 2002 tiene lugar en Nueva York, "la ciudad mártir" y Bush relanza la guerra contra el terrorismo: "América está en guerra; América está en receso; América nunca ha estado tan fuerte. La historia nos ha dado la oportunidad de defender la libertad y de combatir la tiranía y esto es lo que nuestro país hará. Tal vez algunos se cansarán. Otros, tal vez, se fatigarán ante nuestros esfuerzos por la libertad. No así yo, ni mi gobierno, ni nuestro país". (Le Monde, 9 de febrero de 2002) El tema económico quedó silenciado, pese a que el punto central de la agenda era "recuperar el crecimiento y corregir las desigualdades sociales".

243

LSon vlables los Objellvos del Mlienio on el entomo mundlal dal lescer milenlor 
Luego de un viaje por cuatro países de Europa, Alemania, Rusia, Francia e Italia, G. W. Bush logra que se firme en Roma el pacto Moscú-Washington, en mayo de 2002: "Vivimos un mundo nuevo, donde nuevas amenazas y desafíos exigen respuestas cada vez más unidas. Por esta razón, los estados miembros de la OTAN y la Federación Rusa abrimos un nuevo capítulo en nuestras relaciones". A la hora de los brindis se escucharon nuevas salmodias: "El terrorismo tiene unos medios excepcionales que requieren una respuesta excepcional", según la expresión de Jacques Chirac. "El pueblo británico ya no teme al pueblo ruso, pero los dos tememos al terrorismo", Tony Blair. "No podéis vencernos, no tenéis ninguna oportunidad", espetó Berlusconi a los terroristas. "No debemos esperar sentados a ser agredidos", recomendó José María Aznar. "No podemos pensar Rusia fuera de Europa”, concluyó Vladimir Putin. (ECA, 2004, p. 1033)

Mijail Gorbachov había dicho: "Las víctimas de los atentados del 11 de septiembre en los Estados Unidos no habrían muerto en vano si el mundo aprovecha la ocasión para mirarse en el espejo y establecer un compromiso moral sin caer en el pánico". No ha sido la moral sino el pánico, el hilo conductor. El terna central del foro económico de Davos 2003 era "construir la confianza", pero la confianza económica estaba amenazada de guerra. El discurso de G. W. Bush a la nación, 16 de marzo de 2003, está plagado de mentiras y calumnias: "Nuestra buena fe no ha sido reconocida. El régimen iraquí ha utilizado la vía diplomática como estrategia para ganar tiempo a su favor. Informes acumulados por éste y otros gobiernos no dejan duda alguna de que el régimen iraquí posee y esconde armas mortales jamás imaginadas. Este régimen ya ha utilizado armas de destrucción masiva contra los pueblos vecinos de Irak y contra el pueblo iraquí. Odia profundamente a Estados Unidos $\mathrm{y}$ a nuestros amigos $\mathrm{y}$ ha ayudado, entrenado $\mathrm{y}$ albergado a terroristas, incluidos agentes de Al Qaeda. El peligro es claro. El Consejo de Seguridad de Naciones Unidas incumplió sus responsabilidades y, por tanto, nosotros vamos a tomar las nuestras". (Entomo económico mundial; p. 250)

Al celebrarse el foro económico de Davos, en enero de 2004, comienza a correrse la cortina de la verdad y de la mentira, que algunos todavía desconocen. Paul O'Neil, primer Secretario del Tesoro de G. W. Bush, ha afirmado que "la caída del presidente de Irak, Saddam Hussein, era prioridad de la presidencia, en enero 2001, ocho meses antes de los 
atentados del 11 de septiembre, en revelaciones hechas al periodista Ron Suskin, cuyo libro titulado "El precio de la lealtad" aparecerá próximamente. Paul O'Neil tuvo acceso a un documento calificado de "secreto": "un plan para Irak después de Saddam", discutido desde enero 2001. La Casa Blanca anunciaba planes de despliegue de fuerzas de paz, tribunales de justicia y también distribución de las riquezas petroleras iraquíes". "O'Neil decía en el diario Time que "nunca vio en los datos de este informe una verdadera prueba" de la presencia de armas de destrucción masiva en Irak. "Había algunas afirmaciones y opiniones expresadas por algunas personas, pero yo no nací ayer y conozco la diferencia entre una prueba y una opinión, ilusión o conclusión que pueda sacarse de algunas presunciones". (Ibidem; p. 306)

La amenaza no era militar, sino económica y con olor a petróleo. En pleno declive de la economía norteamericana, el 6 de noviembre de 2000, el gobierno de Irak, segundo o tercer productor de petróleo, transfiere sus multimillonarios activos de la zona dólar a la zona euro. Los economistas Paul Harris y Joseph Stiglitz se preguntan: i"qué pasaría si la OPEP, como grupo, decidiera seguir el ejemplo de Irak y empezara a negociar petróleo en euros? Las naciones consumidoras de petróleo tendrían que hacer salir sus dólares de las reservas de sus bancos centrales y reemplazarlos por euros. El valor del dólar se vendría abajo y las consecuencias serían las que podrían esperarse de cualquier colapso de divisa e inflación masiva. Los fondos extranjeros podrían salir atropelladamente del mercado de valores norteamericano y habría una huida de los bancos de los activos en dólares como la de 1930; el déficit presupuestario se incumplinía y así sucesivamente". ("Bush versus Europa". (Cambios, periódico digital)

La Administración Bush trata de justificar la invasión de Irak con una serie de mentiras, carencia de toda moral y de irrespeto al derecho internacional, que le ha hecho perder la credibilidad internacional. El informe de David Kay, responsable de la misión de 1.400 especialistas enviados a Irak en junio de 2003 para investigar la presencia de armas de destrucción masiva, concluye: "Creo que no existían tales armas", dijo al presentar la renuncia a su cargo. Esto fue un duro golpe para Bush, quien en posterior discurso a la nación seguía diciendo: "El informe Kay ha identificado docenas de actividades relacionadas con programas de destrucción masiva y una significativa cantidad de equipo que Irak ocultaba a Naciones Unidas. Si no hubiéramos actuado esos programas 
de armas destructivas del dictador se estarían desarrollando hoy". No era éste el informe de D. Kay, ni el de Charles Duelfer. (ECA 2005; p. 227) El pasado mes de diciembre G. W. Bush "admite guerra por error antiterrorista. El Gobierno de Estados Unidos pregonó la existencia de armas de destrucción masiva en Irak, como una razón para derrocar a Saddam Hussein, pero éstas no aparecieron. Bush dijo que asume la culpa por la invasión basándose en datos de inteligencia falsos". ( $E l$ Diario de Hoy, 15 de diciembre de 2005) En nombre del terrorismo, el fin justifica los medios.

El discurso que Tony Blair pronunciara en el foro económico de Davos 2005 nos había generado cierta esperanza. Blair afirmó que los desafíos del mundo son interdependientes. Estados Unidos sabe que no puede vencer sólo el flagelo del terrorismo y, por ello, debe cooperar en la lucha contra los otros desafíos planetarios. "Si Estados Unidos quiere que el resto del mundo participe en los objetivos que él se ha fijado, Estados Unidos debe, por su parte, participar en los otros objetivos. Es absurdo tener que escoger entre una acción que se concentre en el terrorismo y otra sobre la pobreza en el mundo. La lucha antiterrorista, la propagación de la democracia y la paz en el Próximo Oriente son objetivos relacionados entre sí y no pueden disociarse de la ayuda a África, presa de la miseria o de pandemias como el sida y el paludismo, o la lucha contra el recalentamiento del planeta, generador de catástrofes". Con dedicación especial al gobierno Bush, Tony Blair agregó que "se puede luchar contra el calentamiento climático sin que ello frene el crecimiento económico, gracias al aporte de la ciencia y de la tecnología". (ECA 2005, p. 234) A lo largo del año 2005, hemos visto que la Administración Bush no se ha dejado convencer con este discurso de Blair, sino que más bien está pasando de la esperanza a la locura.

\section{La Nueva Estrategia de Seguridad Nacional norteamericana}

A medida que avanza el primer trimestre de 2006, se agrava la situación interna en Irak, de manera que algunos expertos hablan del inicio de una guerra civil entre las dos facciones islámicas de chítas y sunitas. El gobierno iraquí no puede detener el creciente número de asesinatos que aumentan luego de la destrucción de una de las mezquitas sagradas del grupo chí́ta y los ataques combinados contra reductos terroristas no logran traer un jirón de paz. En varias ciudades de Estados Unidos y en muchas capitales de otros países se realizan manifestaciones en 
contra de la guerra de Irak, pidiendo el pronto retiro de las tropas norteamericanas, cuyos muertos sobrepasan los 2.800 efectivos. En estas circunstancias, crece el porcentaje de estadounidenses que reprueban la política Bush a los tres años de iniciada la guerra de Irak.

En este adverso escenario, la Casa Blanca presenta la Nueva Estrategia de Seguridad Nacional norteamericana, que mantiene la acción militar preventiva, justificada por el "derecho inherente a la autodefensa", como uno de los ejes de la protección de Estados Unidos. "Washington reitera su guerra preventiva y estigmatiza a Irán". (Le Monde, 18 de marzo de 2006) "Bush designa a Irán como el enemigo número uno" (Le Figaro, 19 de marzo de 2006) Al mismo tiempo que baja fuera y dentro de Estados Unidos la calificación de Bush, la Casa Blanca hace los mayores esfuerzos por lograr dos imposibles: convencer a la población nacional de que la situación global de Irak va mejorando, pese a las imágenes que reproduce la televisión internacional. Segundo, que ahora la amenaza mayor y el foco terrorista número uno es Irán, por su patente deseo de pasar de la electricidad al átomo. "Ningún país presenta mayor desafío que Irán", dice el informe preparado por Stephen Hadley, consejero de la seguridad nacional.

Cuando el contencioso nuclear de Irán pasa al Consejo de Seguridad de la ONU, las acusaciones contra Irán suenan como un eco del informe presentado hace tres años contra Irak. "El régimen iraní sostiene el terrorismo, amenaza a Israel, trata de entrabar la paz en el Próximo Oriente, perturba la democracia en Irak y ahoga las aspiraciones de su pueblo por la libertad", dice Stephen Hadley. Los redactores de Le Monde y Le Figaro nos dicen que ahora cambia la ecuación: “el objetivo ultimo de Washington es cambiar sus políticas, abrir el sistema y procurar la libertad" de los iraníes. El instrumento privilegiado a tal fin no es una intervención armada, aunque no es explícitamente calificada como "ultimo recurso". La resolución permanece intacta: "Estamos determinados a mantener las armas más peligrosas fuera del alcance de los grupos más peligrosos del mundo", reza el informe.

Para que no quede duda de que se mantiene el dogma de la "acción preventiva", adoptado en 2002, y reafirmado en 2006: "Cuanto mayor es la amenaza, más arriesgada es la inacción y más fuertes son las razones para una acción anticipada por nuestros enemigos". Esta fórmula se enunció un año después del 11 de septiembre y seis meses antes de la invasión de Irak. Sus efectos perversos son asumidos ahora por la Casa 
Blanca: "Esta Administración ha heredado una amenaza iraquí aún no resuelta. La eliminación de Saddam Hussein ha arreglado el problema, de una vez por todas", agrega el documento. Quienes siguen en la lista no se imaginen estar protegidos por el precedente de que las armas de destrucción masiva no se hallaron en Irak: "Siempre habrá incertidumbres sobre la situación de los programas secretos. La burla, la negación y la mentira son un juego peligroso a que dedican los dictadores a su riesgo y peligro", recuerda el informe.

El editorialista de Le Monde reproduce uno de los párrafos del informe que mantiene claramente la política de la guerra preventiva. La necesidad de la acción preventiva “permanece la misma”. El documento concede con todo una mayor importancia a ponerse de acuerdo con los aliados para utilizar la vía diplomática "de preferencia" para reducir la amenaza de armas de destrucción masiva. "Si es necesario, sin embargo, según los antiguos principios de la legítima defensa, nosotros no excluimos el uso de la fuerza antes de que un ataque se produzca, incluso si permanece la incertidumbre del momento y lugar del ataque enemigo. Cuando las consecuencias de un ataque con armas de destrucción masiva son potencialmente tan destructivas, nosotros no podemos permitir quedarnos sin reaccionar antes de que se materialicen tan grandes peligros". (Le Monde, 17 de marzo de 2006)

El corresponsal de Le Figaro nos dice que la Nueva Estrategia de Seguridad Nacional conlleva un mensaje positivo sobre la propagación de la democracia. En adelante "el progreso de la libertad y de la dignidad humana a través de la democracia constituye la solución a largo plazo del terrorismo transnacional", resume el documento. La lucha contra los terroristas y los "Estados despóticos" que los sostienen pretende dar a la democracia "el tiempo y el espacio para que eche raíces". Para la Casa Blanca son siete los Estados despóticos especialmente vigilados: Corea del Norte, Irán, Siria, Cuba, Bielorrusia, Birmania y Zimbabwe. También se critica a Rusia por el retroceso impuesto a las "libertades democráticas", y a China por "su modo de pensar y actuar anquilosado". La Casa Blanca propone a todos el círculo virtuoso: "la libertad lleva a la democracia, que termina en la paz. Le toca el resto del mundo escoger su campo". (Le Figaro, 19 de marzo de 2006).

Hay algo de enfermizo en todo el equipo de la Administración Bush, cuando se niegan a reconocer las duras lecciones que les ha de- 
jado la ilegal guerra de Irak y las manifestaciones en contra de tantas muertes inocentes. Esta enfermedad es doblemente maligna porque no reconocen su grave error y porque quieren que el resto de sus aliados apoyen una posible acción militar contra Irán. Con esta filosofía moral y con este derecho internacional humanitario, a su imagen y semejanza, seguramente lograrán tres cosas: que los Objetivos del Milenio sigan aparcados en la vía muerta, que otros países hagan lo posible por entrar en el "club nuclear" y que sigan creciendo los movimientos terroristas opuestos al terrorismo de Estado. 